\title{
Communication with the seriously ill: physicians' attitudes in Saudi Arabia
}

\author{
Abdullah F Mobeireek, Feisal A Al-Kassimi, Suliman A Al-Majid, and Abdullah Al-Shimemry \\ King Saud University and King Fahad National Guard Hospital, Riyadh, Saudi Arabia.
}

\begin{abstract}
Objectives-To study some ethical problems created by accession of a previously nomadic and traditional society to modern invasive medicine, by assessment of physicians' attitudes towards sharing information and decision-making with patients in the setting of a serious illness.

Design-Self-completion questionnaire administered in 1993.

Setting-Riyadh, feddah, and Buraidah, three of the largest cities in Saudi Arabia.

Survey sample-Senior and junior physicians from departments of internal medicine and critical care in six hospitals in the above cities.

Results-A total of 249 physicians participated in the study. Less than half (47\%) indicated they provided information on diagnosis and prognosis of serious illnesses all the time. Physicians who were more senior and those who spoke Arabic fared better than other groups. The majority (75\%) preferred to discuss information with close relatives rather than patients, even when the patients were mentally competent. Most of the physicians (72\%) felt patients had the right to refuse a specific treatment modality, and $68 \%$ denied patients the right to demand such a treatment if considered futile. Further analysis showed that physicians' attitudes varied along a spectrum from passive (25\%) to paternalistic (21\%) with the largest group (47\%) in a balanced position.

Conclusions-In traditional societies where physicians are regarded as figures of authority and family ties are important, there is a considerable shift of access to information and decision-making from patients to their physicians and relatives in a manner that threatens patients' autonomy. Ethical principles, wider availability of invasive medical technology and a rise in public awareness dictate an attitude change.
\end{abstract}

\section{Key words}

Physician-patient communication; patients' autonomy; Saudi Arabia

\section{Introduction}

Adequate communication between physicians and patients provides innumerable benefits to both parties and to the health system. It is necessary if physicians are to practise on sound ethical principles. ${ }^{1-3}$ The risk of legal liability is also reduced. ${ }^{4}$ This process assumes more importance when dealing with patients with progressive lifethreatening illnesses such as malignancy and endstage cardiac or hepatic failure etc. Management of these diseases is often controversial, approaches range from conservative to highly aggressive, ando patients' values and preferences may be a helpfule guide. ${ }^{56}$ Involving patients ensures their satisfaction and cooperation and reduces the likelihood of their seeking multiple consultations, investigations or unwarranted aggressive interventions in future deteriorations.

In the last few decades there has been a transformation in Saudi Arabia from a nomadic to an urbanised life. Modern medical facilities, including intensive care, are now widely available. The patient's right to self-determination was established many centuries ago. ${ }^{7}$ However, only a few studies evaluating the physician-patient relationship have been reported. A recent study suggested a rise in physician-patient conflicts and medical litigation. ${ }^{8}$ The objective of the present survey is to find out how physicians interact with their patients in Saudi, where a traditional Arabian culture is adopting Western technology and practices.

\section{Subjects and methods}

Physicians from the departments of internal medicine and critical care in six major hospitals in Saudi Arabia participated in this survey. The hospitals were: King Khalid University Hospital (KKUH), Riyadh Central Hospital (RCH), King Faisal Specialist Hospital (KFSH), and King Fahad National Guard Hospital (KFHR) in Riyadh, King Fahad Hospital in Jeddah (KFHJ) and King Fahad Specialist Hospital in Buraidah (KFSHB). Physicians were categorised as consultants or house staff (residents and fellows). The data were collected 
Table 1 Possible determinants of frequency of communication

\begin{tabular}{|c|c|c|c|c|}
\hline Variable & $\begin{array}{l}\text { All the } \\
\text { time }\end{array}$ & $\begin{array}{l}\text { Most of } \\
\text { the time }\end{array}$ & $\begin{array}{l}\text { Sometimes or } \\
\text { occasionally }\end{array}$ & $\begin{array}{c}{ }_{p}^{* p} \\
\text { value }\end{array}$ \\
\hline \multicolumn{5}{|l|}{ Rank: } \\
\hline Consultants & $61(58 \%)$ & $36(34 \%)$ & $9(8 \%)$ & \multirow[t]{2}{*}{$<0.01$} \\
\hline House staff & $55(38 \%)$ & $61(43 \%)$ & $27(19 \%)$ & \\
\hline \multicolumn{5}{|l|}{ Speak Arabic: } \\
\hline $\begin{array}{l}\text { Yes } \\
\text { No }\end{array}$ & $17(34 \%)$ & $27(54 \%)$ & $6(12 \%)$ & $>0.05$ \\
\hline \multicolumn{5}{|l|}{ Age (years): } \\
\hline$<40$ & $59(44 \%)$ & $53(39 \%)$ & $23(17 \%)$ & \multirow{2}{*}{$>0.05$} \\
\hline$>40$ & $48(57 \%)$ & $27(32 \%)$ & $9(11 \%)$ & \\
\hline \multicolumn{5}{|l|}{ Religion: } \\
\hline Muslim & $95(45 \%)$ & $83(40 \%)$ & $32(15 \%)$ & \multirow[t]{2}{*}{$>0.05$} \\
\hline Others & $21(55 \%)$ & $14(37 \%)$ & $3(8 \%)$ & \\
\hline
\end{tabular}

${ }^{\star} \mathrm{p}$ was determined using chi-square.

Table 2 Patients' rights for treatment: physicians' responses

\begin{tabular}{llrr}
\hline & \multicolumn{3}{c}{$\begin{array}{c}\text { Can the patient request aggressive } \\
\text { treatment if futile? }\end{array}$} \\
\cline { 2 - 3 } $\begin{array}{l}\text { Can the patient } \\
\text { refuse a treatment? }\end{array}$ & Yes & No & Total \\
\hline Yes & $62(25 \%)$ & $115(47 \%)$ & $177(72 \%)$ \\
No & $17(7 \%)$ & $53(21 \%)$ & $70(28 \%)$ \\
\hline Total & $79(32 \%)$ & $168(68 \%)$ & $247(100 \%)$ \\
\hline
\end{tabular}

throughout 1993. The structured questionnaire used for data collection is attached as appendix 1 . The questionnaire, which was anonymous, was completed before or shortly after main departmental meetings where the topics discussed were not related to the subject of the study. All eligible physicians who attended filled in the questionnaires. The statistical significance of the relationship of physicians' rank, ability to speak the Arabic language, age, and religion were investigated by chisquare test.

\section{Results}

A total of 249 physicians completed the questionnaire; 61 from $\mathrm{KKUH}, 39$ from $\mathrm{RCH}, 27$ from $\mathrm{KFHR}, 32$ from KFSH, 56 from $\mathrm{KFHJ}$ and 34 from KFSHB. Consultants were $106(43 \%)$ and house staff $143(57 \%)$. Most physicians ( 170 or $69 \%$ ) were from Middle Eastern Arabian countries, while the remainder were mainly from the Indian sub-continent and Africa. Only 116 physicians (47\%) indicated that they provided information on the diagnosis and prognosis of serious diseases. The result (table 1) suggested that consultants communicated better than house staff $(p<0.01)$, and those who spoke Arabic fared better than those who did not (chi-square was 5.70, $0.05<P<0 \cdot 1$ ). Most physicians $(75 \%)$ preferred to talk with close family members, even when dealing with competent patients. There was no significant difference between physicians from the Middle East and others $(0 \cdot 50>p>0 \cdot 10)$. As for patients' rights to treatment (table 2), 177 physicians (72\%) thought patients should be able to refuse specific treatments recommended by the physician, while the rest $(28 \%)$ denied patients this right. Also, 79 (32\%) acknowledged patients' right to demand such treatment even if it was considered futile by physicians, while $168(68 \%)$ denied patients this right. Further analysis showed that $25 \%$ of physicians thought patients had both the right to refuse aggressive treatment and the right to demand it, even if it was considered futile by physicians. However, $21 \%$ believed the decision should be left entirely to the physician. The largest group (47\%) acknowledged the patients' right to refuse treatment but denied their right to have futile treatment.

\section{Discussion}

In this study less than half of the physicians indicated that they provide information all the time to patients or their families regarding serious lifethreatening illnesses. This is similar to studies in Western countries that revealed that most physicians (60-90\%) withhold information from patients with fatal disease. ${ }^{9}$ Possible reasons for this include emotional pressures, the lengthy time required, or concern that this may upset the patients. ${ }^{1910}$ Many patients would, therefore, be unable to participate in medical decisions or plan any necessary social adjustment. Previous studies have shown that patients wish to know and to be involved. ${ }^{9-12}$ Most of the evidence suggests that no harm would result if the discussions were conducted in the appropriate manner. ${ }^{9-12}$ House staff were less likely to discuss this information with patients than consultants. This could be because they feel less experienced to handle such a sensitive task and therefore delegate it to consultants. Duffy et al made similar observations on a study of their house staff. ${ }^{13}$ Linguistic differences can form a barrier to communication, ${ }^{914}$ and this was again evident in our study, although the $P$ value was just short of the 0.05 significance level.

In addition, three-quarters of physicians preferred discussing the medical problems with the family rather than the patient concerned even when the patient was mentally competent. Physicians could be relying on the strong family links present in Arabian communities, leaving close family members to decide what they feel is best for the patient. This contrasts with practice in Western countries where such an approach would be considered to undermine patients' autonomy. ${ }^{1-3}$ Miles et al suggested that physicians and families often underestimate patients' ability to handle these situations. ${ }^{15}$ Decisions made by family members are influenced by emotional factors such as feelings of guilt or denial - and at times by self-serving motivations. ${ }^{15}$ Finally, health values are not predicted accurately by patients' surrogates. ${ }^{16}$ Ethical principles, therefore, dictate that while family members should be kept well informed, their wishes should not override the wishes of the competent patient. ${ }^{1-3} 15$ 
The essence of the communication process is to allow patients to plan with physicians for suitable management strategies. Patients' rights to refuse or request a particular therapy (termed negative and positive rights respectively) against physicians' recommendation have been the focus of many ethical discussions and legal disputes. ${ }^{17}$ Patients' autonomy is now an established principle of clinical practice in many Western countries. In this study $177(72 \%)$ physicians thought patients had the right to refuse aggressive treatments, and $168(68 \%)$ thought that patients did not have the right to demand such treatment if physicians considered it futile. On further analysis of these responses physicians could be categorised into four groups. These were: 1) Sixty-two physicians $(25 \%)$ who adopted a passive role, giving patients unlimited autonomy and thereby undermining physicians' integrity; 2) Fifty-three physicians $(21 \%)$ who were at the other end of the spectrum, with a paternalistic attitude, leaving all decisions to physicians; 3) The largest group 115 (47\%) who were in a balanced position, acknowledging patients' autonomy but defining a limit based on their professional judgment; 4) A minority 17 (7\%) who thought that treatment should be given regardless of either the physician's or the patient's wishes.

Limitations are bound to occur in this type of study which uses a questionnaire as the only mode of data collection, and it is therefore only a preliminary survey. None the less, there is evidence to suggest a lack of effective communication between physicians and patients with serious illnesses. An attitude change is required since both the current ethical principles and Islamic jurisprudence, which forms the legal and moral basis in Saudi Arabia, emphasise patients' autonomy. It is worth stressing that communication barriers including attitudes, linguistic differences and lack of communication skills, can be overcome or alleviated. ${ }^{1819}$ Studies looking at ways to improve communication and addressing patients and relatives, and seeking the views of the public are needed.

\section{Acknowledgement}

The authors would like to thank Professor Hasan Abu Aisha, Professor Mansour Al-Nozha, and Carol Lambert Withers for suggestions on the study, and Dr Elijah Bamgboye for his statistical advice.

All authors are Consultants in Internal and Pulmonary Medicine. Abdullah F. Mobeireek, MRCP, FCCP, is Assistant Professor in the Division of Pulmonology, the Department of Medicine, College of Medicine, King Saud University. Feisal A Al-Kassimi, MRCP(I), is a Professor, also in the Division of Pulmonology. Suliman A Al-Majid, FRCP(C), is Associate Professor in the same division. Abdullah Al-Shimemry, FRCP $(C)$, is Consultant Pulmonologist at the King Fahad National Guard Hospital, which, like King Saud University is in Riyadh, Saudi Arabia.

\section{References}

1 Ruark JE, Raffin TA and the Stanford University Medical Cente Committee on Ethics. Initiating and withdrawing life support; principles and practice in adult medicine. New England fournal of Medicine 1988; 318: 25-30.

2 ACCP/SCCM Consensus panel. Ethical and moral guidelines for the initiation, continuation and withdrawal of intensive care. Chest 1990; 97: 949-58.

3 ATS. Withholding and withdrawing life sustaining therapy. American Review of Respiratory Diseases 1991; 144: 726-31.

4 Roberts DK. Prevention: patient communication. Clinical Obstetrics and Gynecology 1988; 31: 153-61.

5 Levine MN, Gafni A, Markham B, MacFarlane D. A bedside decision instrument to elicit patients' preferences concerning adjuvant chemotherapy for breast cancer. Annals of Internal Medicine 1992; 117: 53-8.

6 Fine RL. Personal choices: communication between physicians and patients when confronting critical illness. Fournal of Clinical Ethics 1991; 2: 57-61.

7 Mobarak GMA. Absence of patient's consent. In: Therapy and medical responsibility in Islamic legislation. Damascus: Al-Faraby Pub Co, 1991: 197-208.

8 Al-Hajjaj MS. Medical practice in Saudi Arabia: the medico-legal aspect. Saudi Medical fournal 1996; 17: $1-4$.

9 Waitzkin H. Doctor-patient communication: clinical implications of social scientific research. Fournal of thg American Medical Association 1984; 252: 2441-6.

10 Pfeifer MP, Sidorov JE, Smith AC, et al. The discus sion of end-of-life medical care by primary cate patients and physicians: a multi-center study using structured qualitative interviews. Fournal of General Internal Medicine 1994; 9: 82-8.

11 Finucane TE, Shumway JM, Powers RL, D'Alessandri RM. Planning with elderly outpatients for contingencies of severe illness: a survey and clinical trial. fournal of General Internal Medicine 1988; 3: 322-5.

12 Kai 1, Ohi G, Yano E, et al. Communication between patients and physicians about terminal care. A survey in Japan. Social Science and Medicine 1993; 36: 1151-9.

13 Duffy DL, Hamerman D, Cohen MA. Communication skills of house officers: a study in a medical clinic. Annals of Internal Medicine 1980; 93: 354-7.

14 Crisp AH, Edwards WJ. Communication in medical practice across ethnic boundaries. Postgraduate Medical fournal 1989; 65: 150-5.

15 Miles SH, Cranford R, Schultz AL. The do-not-resuscitate order in a teaching hospital, considerations and a suggested policy. Annals of Internal Medicine 1982; 96: 660-4.

16 Tsevat J, Cook EF, Green ML, et al. Health values of $\mathrm{C}$ the seriously ill. Annals of Internal Medicine 1995; 122: 514-20.

17 Brett AS, McCullough LB. When patients request specific interventions: defining the limits of the physician's obligation. New England fournal of Medicine 1986; 315: 1347-51.

18 Neighbour R. The inner apprentice: an awareness-central approach to vocational training for general practice. Lancaster: Kluwer, 1992.

19 Crisp AH. Undergraduate training for communication in medical practice. Fournal of the Royal Society of Medicine 1986; 79: 568-74. 


\section{Appendix 1}

\section{Questionnaire on the care of the seriously ill \\ Dear colleague:}

Your cooperation is appreciated in filling the following questionnaire on certain issues related to the care of patients suffering from serious illnesses. A few minutes of your time will help to see if we can improve our care for these patients. Your name is not required.

The following are definitions of some terms used in the questionnaire:

Serious disease: Progressive and life-threatening, for example; malignancy, end-stage advanced organ failure such as cardiac, respiratory, hepatic, AIDS. Aggressive treatment: For example, chemotherapy, cardiopulmonary resuscitation (CPR), mechanical ventilation, balloon pumps, dialysis, high-risk surgery.

Competent patient: Satisfies the following:

(1) Able to understand the given medical information.

(2) Able to reason and consider this information in relation to his or her personal values and goals.

(3) Able to communicate meaningfully.

Thanks again for your time.

\section{[A] Physician's personal data:}

- Age:

- Year of graduation:

- Postgraduate certification:

Country:

- Current hospital:

- Specialty:

- Internal medicine ()

- ICU ( )

- Other ( )

- State

- Level:

- Resident ()

- Registrar ()
- Senior Registrar ( )

- Consultant ( )

- Religion:

- Muslim ( )

- Other ()

- Speak Arabic:

- Yes ( )

- No ()

[B] Communication with patients with serious illnesses

When you are caring for patients with serious diseases such as malignancy or end-stage organ failure: for example, heart, lung, liver

[1] How often do you give the patient, or his family, if he is incompetent, information about diagnosis and prognosis:

- All the time

- Most of the time

- Sometimes

- Occasionally

- Never

[2] Who do you discuss this information with usually?

- Patient first (if competent) and

then the family if he/she agrees

- Family first and then the patient

if they agree

- Another approach

State:

[3] Does a patient, who is competent, have the right to refuse a treatment recommended by his or her physician?

- Yes

- No

[4] Does a patient, who is competent, have the right to request an aggressive treatment if his or her physician consider it futile?

- Yes

- No 